\title{
Effects of pastes containing ion-releasing particles on dentin remineralization
}

\author{
Masahiro IIJIMA¹, Rina ISHIKAWA¹, Kyotaro KAWAGUCHI ${ }^{1}$, Shuichi ITO², Takashi SAITO² and Itaru MIZOGUCHI ${ }^{1}$ \\ ${ }^{1}$ Division of Orthodontics and Dentofacial Orthopedics, Department of Oral Growth and Development, School of Dentistry, Health Sciences University \\ of Hokkaido, 1757 Kanazawa, Ishikari-Tobetsu, Hokkaido 061-0293, Japan \\ ${ }^{2}$ Division of Clinical Cariology and Endodontology, Department of Oral Rehabilitation, School of Dentistry, Health Sciences University of Hokkaido, \\ 1757 Kanazawa, Ishikari-Tobetsu, Hokkaido 061-0293, Japan \\ Corresponding author, Masahiro IIJIMA; E-mail: iijima@hoku-iryo-u.ac.jp
}

\begin{abstract}
We investigated the effects of the weekly application of pastes containing a surface reaction-type pre-reacted glass-ionomer (S-PRG) filler on dentin remineralization. Human dentin blocks were demineralized and polished using pastes containing S-PRG filler (0, 5, and 30\%), and then immersed in remineralizing solution for 1 month. Nanoindentation testing was carried out during the immersion period, and the dentin surfaces were examined using scanning electron microscopy. A nano-hydroxyapatite-containing paste was used for comparison. Immersion in demineralization solution had a marked negative effect on the mechanical properties in all specimens. The mechanical properties of specimens polished with S-PRG filler-containing pastes recovered significantly after immersion in remineralization solution for 1 month compared with the other specimens. After remineralization, the open dentinal tubules were filled with a remineralization layer in specimens polished with S-PRG filler-containing and nano-hydroxyapatite-containing pastes. S-PRG filler-containing pastes can aid dentin remineralization.
\end{abstract}

Keywords: Dentin remineralization, Nanoindentation, Professional tooth polishing

\section{INTRODUCTION}

The use of acid etching and conditioning of dentin surfaces to improve adhesion is widely accepted in restorative dentistry ${ }^{1}$. On the other hand, the incidences of dentin hypersensitivity and root caries have increased recently ${ }^{2-5)}$, and the development of effective methods to prevent these common clinical problems is important. The use of increased calcium and fluoride concentrations in oral fluids seems to be a reasonable approach to enhance the remineralization of demineralized dentin surfaces ${ }^{6,7)}$.

Various dental products and applications have been introduced in the last half century to increase the remineralization of enamel and dentin structures. As fluoride enhances hydroxyapatite (HA) mineralization and reduces solubility, fluoride-containing products such as toothpaste, mouth rinse, fluoride-releasing adhesives, and sealants have been introduced widely ${ }^{6-8)}$. Recently, the use of nano-HA, which is similar to the apatite crystal of dental enamel, has been proposed for the remineralization of early carious lesions ${ }^{9,10)}$. A surface reaction-type pre-reacted glass-ionomer (S-PRG) filler forms a stable glass-ionomer phase by pre-reacting acidreactive glass-containing fluoride with polycarboxylic acid in the presence of water ${ }^{11-15)}$, and it can release $\mathrm{Al}^{3+}, \mathrm{BO}_{3}{ }^{3-}, \mathrm{F}^{-}, \mathrm{Na}^{+}, \mathrm{SiO}_{3}{ }^{2-}$, and $\mathrm{Sr}^{2+}$. The release of $\mathrm{SiO}_{3}{ }^{2-}$ and $\mathrm{Na}^{+}$into the surrounding environment leads to buffering ${ }^{16,17)}$; in addition, $\mathrm{Sr}^{2+}$ and $\mathrm{F}^{-}$are known to be strong inducers of remineralization of etched dentin and enamel surfaces ${ }^{18,19)}$. The development of effective

Color figures can be viewed in the online issue, which is available at J-STAGE.

Received Jan 12, 2018: Accepted Jun 29, 2018

doi:10.4012/dmj.2018-015 JOI JST.JSTAGE/dmj/2018-015 methods of dentin mineralization to prevent dentin hypersensitivity and root caries is highly desirable. Tooth polishing with S-PRG filler-containing paste may be a promising approach to enhance dentin remineralization.

The purpose of this in vitro study was to investigate the effect of the weekly professional application of pastes containing S-PRG filler on dentin remineralization. Nano-HA-containing pastes were used for comparison. The null hypothesis was that the polishing of etched dentin samples with an S-PRG filler-containing paste would not enhance remineralization.

\section{MATERIALS AND METHODS}

\section{Materials}

Human non-carious premolars that were extracted from patients who underwent orthodontic treatment were subjected to nanoindentation tests to investigate the remineralization of etched dentin surfaces. Figure 1 is a schematic diagram of specimen preparation and paste application. Each tooth was sectioned at the cementumenamel junction and the middle region of the root using a low-speed water-cooled diamond saw (IsoMet, Buehler, Lake Bluff, IL, USA), and then the portion was sectioned parallel to the long axis of the tooth to obtain root slabs. The slabs were encapsulated in epoxy resin (EpoFix, Struers, Copenhagen, Denmark). After $24 \mathrm{~h}$, the specimens were ground using 600-grit sandpaper and polished using diamond suspensions with particle sizes of 3,1 , and $0.25 \mu \mathrm{m}$ (Buehler) to obtain surfaces suitable for nanoindentation. This polishing procedure removed root cementum from the tooth surfaces. Acid- 


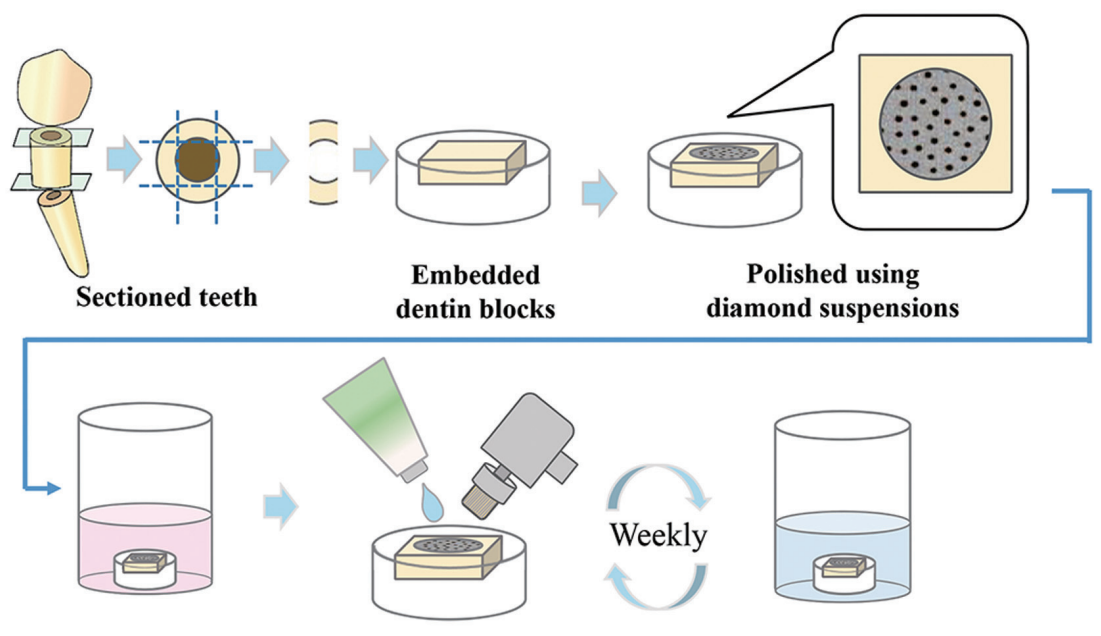

Immersed in demineralization Polished using each paste solution for 3 days

Immersed in an artificial saliva solution for 1 month

Fig. 1 Schematic illustration of the specimen preparation sequence for in vitro remineralization of dentin surfaces.

Table 1 Materials used in the present study

\begin{tabular}{|c|c|c|}
\hline Materials & $\begin{array}{l}\text { Brand name/ } \\
\text { Manufacturer }\end{array}$ & Composition \\
\hline $\begin{array}{l}\text { S-PRG filler-containing } \\
\text { paste }\end{array}$ & & $\begin{array}{l}\text { Hydrated silica, Carboxymethylcellulose sodium, Glycerol } \\
\text { Sorbitol, Sodium dodecyl sulfate, Mint flavoring } \\
\text { S-PRG filler }(0,5 \text {, or } 30 \mathrm{wt} \%)\end{array}$ \\
\hline $\begin{array}{l}\text { Nano-HA-containing } \\
\text { paste }\end{array}$ & Renamel/Sangi & $\begin{array}{l}\text { Water, Hydroxyapatite, Glycerin, Diglycerin, Xylitol, Butylene glycol } \\
\text { Cellulosegum, Silica, Essence, Methylparaben, Propylparaben } \\
\text { Xanthanegum, Sodium lauroyl sarcosine, Cetylpyridinium chloride }\end{array}$ \\
\hline Artificial saliva & & $\begin{array}{l}\mathrm{CaCl}_{2}, \mathrm{NaH}_{2} \mathrm{PO}_{4}, \mathrm{Ca} / \mathrm{PO}_{4} \\
\text { pH adjusted to } 4.3 \text { and } 6.8 \text { by } \mathrm{CH}_{3} \mathrm{COOH} \text { and } \mathrm{NaOH}\end{array}$ \\
\hline
\end{tabular}

resistant nail varnish was then applied to the dentin surfaces, leaving a test surface area of $3 \mathrm{~mm}^{2}$.

We created a paste containing hydrated silica (mean particle size, $6.4 \mu \mathrm{m}$, Evonik Industries, Essen, Germany), carboxymethylcellulose sodium (molecular weight, 725,000 Da, Nacalai Tesque, Kyoto, Japan), glycerol (84-87\% pure, Nacalai Tesque), sorbitol $(97 \%$ pure, Nacalai Tesque), sodium dodecyl sulfate $(93.5 \%$ pure, Nacalai Tesque), mint flavoring (Yamamoto Perfumery, Osaka, Japan), and an S-PRG filler (0, 5, or $30 \mathrm{wt} \%$ ). The S-PRG filler (mean particle size, $1.0 \mu \mathrm{m}$ ) was produced as described elsewhere ${ }^{12)}$. The nano-HAcontaining paste (Renamel, Sangi, Tokyo, Japan) was used for comparison. Table 1 lists the composition of the materials used in this study. This study was approved by the ethics committee of the Health Sciences University of Hokkaido.
Dentin remineralization ability and changes in mechanical properties

The specimens (embedded dentin blocks with polished surface areas of $3 \mathrm{~mm}^{2}$ ) were divided into five groups of 15 specimens each. Artificial saliva containing $\mathrm{CaCl}_{2}$ and $\mathrm{NaH}_{2} \mathrm{PO}_{4}$ with a $\mathrm{Ca} / \mathrm{PO}_{4}$ ratio of 1.67 was prepared, and its $\mathrm{pH}$ was adjusted to 4.3 and 6.8 using $\mathrm{CH}_{3} \mathrm{COOH}$ and $\mathrm{NaOH}$. The specimens were immersed in individual $2-\mathrm{mL}$ plastic vials of artificial saliva $(\mathrm{pH}$ 4.3) as demineralizing solution for 3 days at $37^{\circ} \mathrm{C}$ (Fig. 1 ). The demineralized specimens were polished with the various pastes $(0,5$, and $30 \% \mathrm{~S}-\mathrm{PRG}$, Renamel) for 10 s using a low-speed handpiece with a rotating brush. The specimens were rinsed lightly and dried using a moisture-free air source. They were then immersed in remineralization solution (artificial saliva, $\mathrm{pH}$ 6.8) at $37^{\circ} \mathrm{C}$ for 1 month. The specimens were polished once a week during the 1-month period, and the solution was changed weekly. Nanoindentation testing of the dentin surfaces (ENT-1100a, ELIONIX, Tokyo, Japan) was 
carried out at $28^{\circ} \mathrm{C}$ using 10 - and $100-\mathrm{mN}$ loads before and after demineralization and during the remineralization period. The hardness and elastic modulus of the dentin surfaces were calculated using the software provided with the nanoindentation apparatus.

After 1 month of immersion, the specimens were sectioned vertically using a low-speed water-cooled diamond saw (IsoMet); one of the sectioned halves of each specimen was then encapsulated in epoxy resin (EpoFix). After $24 \mathrm{~h}$, the specimens were ground using 600-grit sandpaper and polished using diamond suspensions with particle sizes of 3,1 , and $0.25 \mu \mathrm{m}$ (Buehler) to obtain surfaces suitable for studying the depth-dependent mechanical dentin properties. Nanoindentation testing was carried out at $28^{\circ} \mathrm{C}$ with a peak load of $2 \mathrm{mN}(n=15)$. The indentations were made at depths of $1-98.5 \mu \mathrm{m}(40$ locations spaced $2.5 \mu \mathrm{m}$ apart).

Scanning electron microscope (SEM) observations of enamel surfaces

Representative surfaces of dentin specimens were examined under a SEM (JSM-6610LA, JEOL, Tokyo, Japan) before demineralization, after 3 days of demineralization, and after 1 month of remineralization by immersion in artificial saliva. The specimens were sputter coated with gold (SC-701 AT, Sanyu Electron, Tokyo, Japan) and examined at $15 \mathrm{kV}$. The surfaces of control specimens, which were not immersed in the demineralization solution, were also observed for comparison.

\section{Statistical analysis}

Experimental data were analyzed using the PASW Statistics software package (ver. 18.0J for Windows, IBM, Armonk, NY, USA). The means and standard deviations of hardness and elastic modulus values were calculated for the five groups and compared using one-way analysis of variance with Tukey's test. The significance level was set at $p<0.05$.

\section{RESULTS}

Figures 2 and 3 show the mean hardnesses and elastic modulus of the dentin specimens before and after demineralization and during the immersion period. Hardness and elastic modulus values measured before and immediately after immersion in the demineralization solution did not differ significantly in any group. Demineralization by immersion in acidic artificial saliva solution markedly decreased the hardness and elastic modulus of the dentin surfaces. Following immersion in remineralization solution, the hardness and elastic modulus of dentin specimens polished with the S-PRG filler-containing pastes (5 and 30\%) and nano-HA-containing paste increased gradually with the immersion time. In nanoindentation tests conducted with both loading conditions (10 and $100 \mathrm{mN}$ ), specimens polished with the S-PRG filler-containing pastes (5 and 30\%) exhibited significantly greater hardness and elastic modulus than did unpolished specimens and those polished with the other pastes after 1 month of immersion in remineralization solution.

Figure 4 shows the mean hardness and elastic modulus at different depths of the dentin specimens after 1 month of immersion in remineralization solution and statistical comparisons of the values from the dentin surface to $11 \mu \mathrm{m}$ depths of five specimen groups. No significant difference in hardness at depths of 11-98.5 $\mu \mathrm{m}$ or elastic modulus at depths of 3.5-98.5 $\mu \mathrm{m}$ from the dentin surface was observed among the five specimen groups. Hardness values at depths $\leq 8.5$ from the dentin surface and elastic modulus values at depths $\leq 1 \mu \mathrm{m}$ $\mu \mathrm{m}$ from the dentin surface were greater for specimens polished with S-PRG filler-containing pastes than for specimens in the other groups.

Figure 5 shows representative SEM photomicrographs of the original dentin surface, demineralized dentin surface, and dentin surface after immersion in remineralization solution for 1 month.
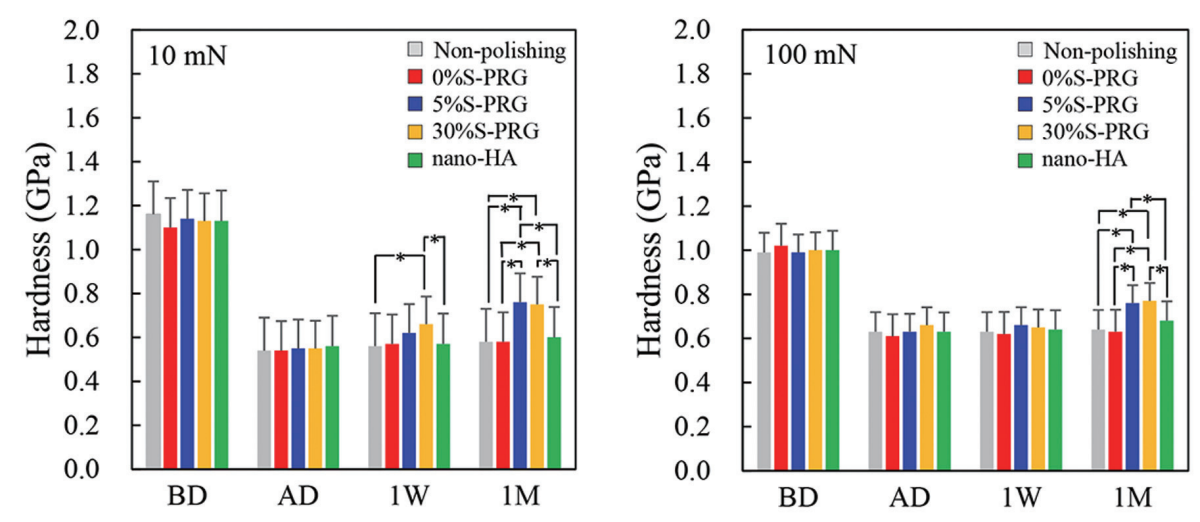

Fig. 2 Mean hardness values of dentin surfaces before and after demineralization, and after immersion in remineralization solution (artificial saliva).

$\mathrm{BD}$, before demineralization; $\mathrm{AD}$, after demineralization; 1W, 1-week immersion; 1M, 1-month immersion. ${ }^{*} p<0.05$ (Tukey test). 

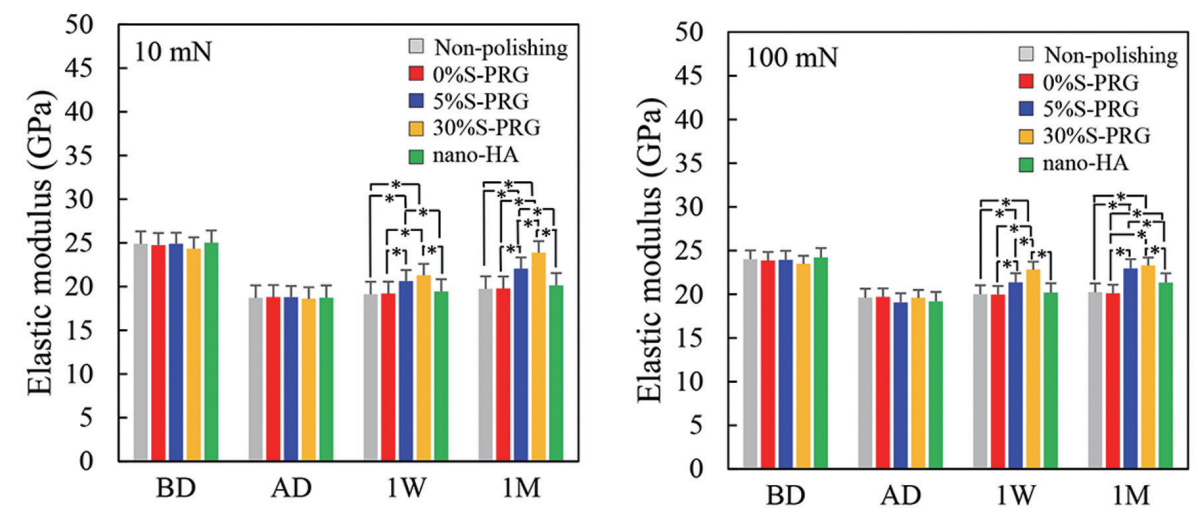

Fig. 3 Meanelastic modulus values of dentin surfaces before and after demineralization, and after immersion in remineralization solution (artificial saliva).

$\mathrm{BD}$, before demineralization; $\mathrm{AD}$, after demineralization; 1W, 1-week immersion; 1M, 1-month immersion. ${ }^{*} p<0.05$ (Tukey test).
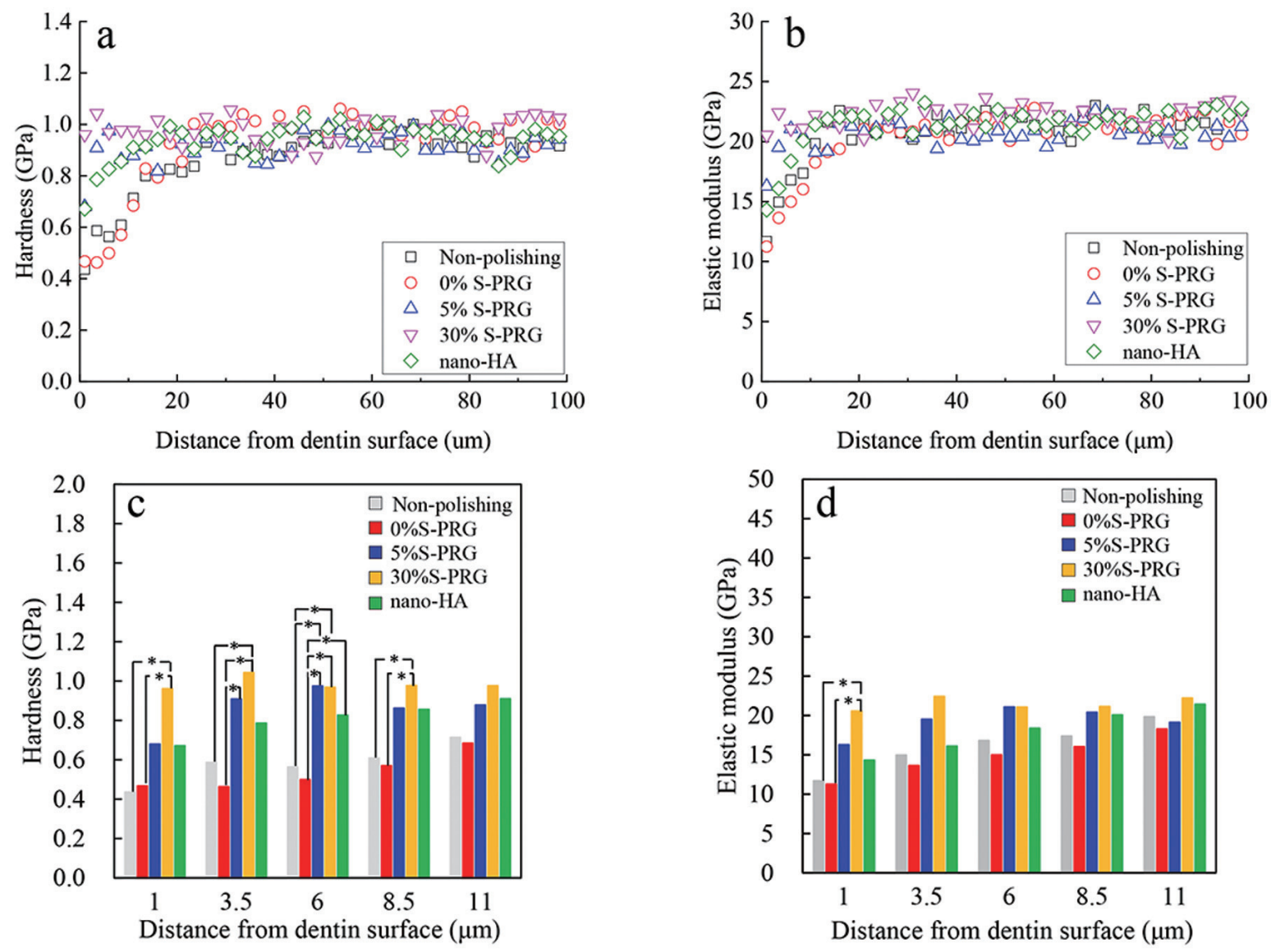

Fig. 4 Mean hardness and elastic modulus values of dentin specimens at different depths after 1-month immersion (a, Hardness; b, Elastic modulus).

Statistical comparisons of the values from the dentin surface to $11 \mu \mathrm{m}$ depths of five specimen groups (c, Hardness; d, Elastic modulus). * $p<0.05$ (Tukey test).

Numerous open dentinal tubules were observed in the specimens after demineralization. After polishing and immersion for 1 month, these tubules were completely filled with a remineralization layer in specimens treated 

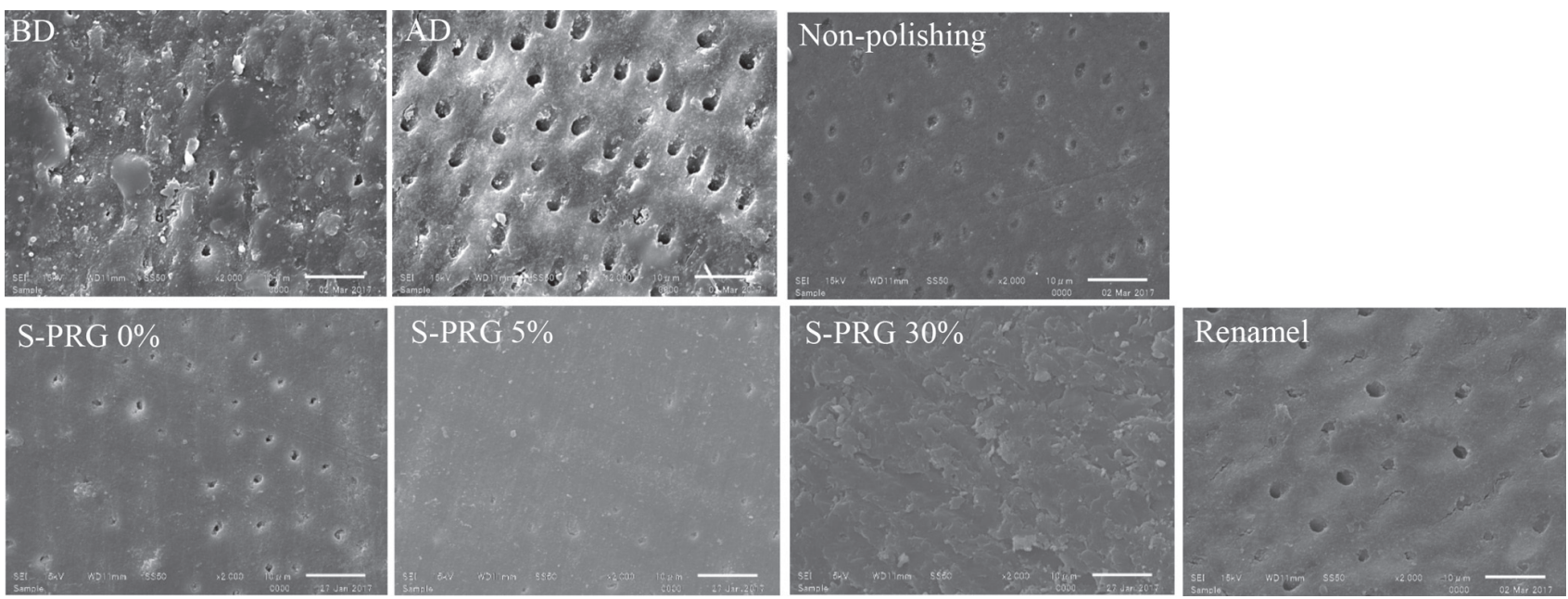

Fig. 5 Representative SEM photomicrographs of the original dentin surface (BD, before demineralization), demineralized dentin surface $(\mathrm{AD}$, after demineralization), and dentin surface after immersion in remineralization solution for 1 month.

with 30\% S-PRG filler-containing paste, and partly filled with a remineralization layer in specimens treated with 5\% S-PRG filler-containing paste and nano-HAcontaining paste. Open dentinal tubules were observed in unpolished specimens and those polished with $0 \%$ S-PRG filler-containing paste.

\section{DISCUSSION}

This study examined the effects of polishing of demineralized dentin samples using pastes containing 5 and $30 \mathrm{wt} \%$ S-PRG filler on remineralization ability in artificial saliva solution. In the nanoindentation test, the specimen surface was ground and then polished because with the nanoindentation test, the mechanical properties are influenced by the surface roughness of the specimen. In addition, the polished surface might simulate dentin surface exposed by daily brushing. Nanoindentation tests followed by immersion in remineralization solution showed that specimens polished with the S-PRG fillercontaining pastes (5 and 30\%) had significantly greater hardnesses and elastic modulus than did unpolished specimens and those polished with the other pastes $(0 \%$ S-PRG and nano-HA). The recovery of hardness and elastic modulus [i.e., (post-immersion value/original value) $\times 100$ ], as measured using a nanoindenter with a 10$\mathrm{mN}$ load, was characterized as follows. Samples treated with the $30 \mathrm{wt} \% \mathrm{~S}-\mathrm{PRG}$ filler-containing paste exhibited $66 \%$ recovery of hardness and $98 \%$ recovery of the elastic modulus, samples treated with the 5 wt $\%$ S-PRG fillercontaining paste exhibited $67 \%$ recovery of hardness and $89 \%$ recovery of the elastic modulus, samples treated with the $0 \mathrm{wt} \% \mathrm{~S}-\mathrm{PRG}$ filler-containing paste exhibited $53 \%$ recovery of hardness and $80 \%$ recovery of the elastic modulus, and samples treated with nanoHA-containing paste exhibited 53\% recovery of hardness and $80 \%$ recovery of the elastic modulus. Thus, the null hypothesis that polishing of dentin samples using an S-PRG filler-containing paste would not enhance remineralization was rejected. The remineralization ability did not differ significantly between specimens treated with the 5 and 30\% S-PRG filler-containing pastes. Paste components other than the S-PRG filler may have little influence on dentin remineralization, as specimens treated with the 0 wt\% S-PRG fillercontaining paste exhibited little enhancement of remineralization following demineralization. Although artificial saliva contains the inorganic ions required for remineralization ${ }^{20)}$, the recovery of unpolished specimens was inferior to that of specimens polished with the 5 and $30 \%$ S-PRG filler-containing pastes and nano-HA-containing paste. Remineralized layers may differ qualitatively. Dental plaque accumulation on enamel and dentin, without mechanical or chemical disturbance, leads to demineralization. Although daily plaque control with toothbrushing and mouthwash use is important, additional professional tooth cleaning with pastes may help to avoid tooth demineralization and enhance remineralization.

According to the results of the depth-dependent nanoindentation test, the hardness and elastic modulus of the non-polished specimens decreased with depth up to $20 \mu \mathrm{m}$, suggesting that these regions of the dentin structure were least demineralized by immersion in demineralizing solution for 3 days. For the nanoindentation test, we used peak loads of 10 and $100 \mathrm{mN}$. The indentation depths were approximately $600 \mathrm{~nm}(0.6 \mu \mathrm{m})$ for the $10 \mathrm{mN}$ peak load and 2,000 $\mathrm{nm}(2 \mu \mathrm{m})$ for the $100 \mathrm{mN}$ peak load. Considering the demineralization depth $(20 \mu \mathrm{m})$ of the dentin surfaces, the mechanical properties obtained with peak loads of 10 and $100 \mathrm{mN}$ were meaningful, and the peak loads for nanoindentation testing were reasonable. However, the indentations produced by $100 \mathrm{mN}$ affected approximately 
$16 \mu \mathrm{m}$ of the width, and the area contained the dentinal tubules, although we tried to minimize the overlap of the indentation with the dentinal tubules, as mechanical properties would be influenced by overlap between the indentation and the dentinal tubules.

S-PRG filler features a glass-ionomer phase around the glass core, which slowly releases multiple ions, such as $\mathrm{Al}^{3+}, \mathrm{BO}_{3}{ }^{3-}, \mathrm{F}^{-}, \mathrm{Na}^{+}, \mathrm{SiO}_{3}{ }^{2-}$, and $\mathrm{Sr}^{2+11-13)}$. We speculate that these ions were released from the S-PRG fillercontaining pastes, inhibiting demineralization and enhancing remineralization of the dentin and enamel. $\mathrm{Si}$ and $\mathrm{Al}$ form the structure of the glass, and $\mathrm{Sr}$ and $\mathrm{F}$ were added as modifiers. Boron, which is highly soluble and has antibacterial and anti-inflammatory properties, was also included ${ }^{21)}$. The release of $\mathrm{Na}^{+}$and $\mathrm{SiO}_{3}{ }^{2-}$ into the surrounding environment has a buffering effect, inhibiting demineralization. The present study revealed no significant difference in remineralization ability between specimens treated with the 5 and 30\% S-PRG filler-containing pastes, although the amount of ion release was influenced by the mixing ratio of solution to S-PRG filler in a previous study ${ }^{11)}$.

Recently, various novel remineralization agents, including nano-HA and casein phosphopeptide amorphous calcium phosphate nanocomplexes, have been developed ${ }^{9,10)}$. Nano-HA is biocompatible and bioactive, and its nano-sized particles are similar to the apatite crystal of tooth enamel ${ }^{9,10,22)}$. Nano-HA has been shown to remineralize carious legions in enamel and dentin $^{9,10)}$. In the remineralization of a demineralized dentin surface, nano-HA may serve as a template, controlling the nucleation and growth of mineral crystals to form a dentin-like structure. The precipitation process may attract $\mathrm{Ca}^{2+}$ and $\mathrm{PO}_{4}{ }^{3-}$ from the environment to the dentin surface and fill vacant positions in the crystal structure $^{23)}$. However, dentin polishing with nano-HAcontaining paste did not enhance the remineralization ability relative to polishing with the S-PRG fillercontaining pastes in the present study. This result may be explained by the low solubility of nano-HA due to its high degree of crystallinity; in addition, amorphous and small imperfect crystals are known to have higher dissolution rates than crystalline compound $\mathrm{s}^{24)}$. However, further research is needed to confirm the crystal structure of nano-HA.

We examined demineralized dentin surfaces during remineralization using SEM. The surface morphology following immersion in an artificial saliva solution after polishing is expected to vary among paste treatments. The surfaces of unpolished specimens and those polished with the $0 \% \mathrm{~S}-\mathrm{PRG}$ filler-containing paste showed numerous open dentinal tubules, consistent with a demineralized dentin surface. By contrast, the dentinal tubules were completely filled by a remineralization layer in specimens polished with the $30 \%$ S-PRG filler-containing paste, and partially filled in specimens polished with the 5\% S-PRG filler-containing paste and nano-HA-containing paste. The coverage of exposed dentin and sealing of dentinal tubules with a remineralization layer may reduce hypersensitivity and inhibit root caries $^{2)}$.

\section{CONCLUSIONS}

Under the study conditions, the following conclusions were drawn:

1. Polishing with an S-PRG filler-containing paste enhances the remineralization ability of demineralized dentin surfaces.

2. Dentin polishing with nano-HA-containing paste did not enhance remineralization ability compared with polishing with the S-PRG fillercontaining pastes.

3. Further investigation is warranted to identify optimal application methods and specific protocols.

\section{REFERENCES}

1) Van Meerbeek B, Peumans M, Poitevin A, Mine A, Van Ende A, Neves A, De Munck J. Relationship between bond-strength tests and clinical outcomes. Dent Mater 2010; 26: e100-121.

2) Zhang N, Melo MA, Chen C, Liu J, Weir MD, Bai Y, Xu HH. Development of a multifunctional adhesive system for prevention of root caries and secondary caries. Dent Mater 2015; 31: 1119-1131.

3) Takahashi N, Nyvad B. Ecological hypothesis of dentin and root caries. Caries Res 2016; 50: 422-431.

4) Varoni EM, Zuccheri T, Carletta A, Palazzo B, Cochis A, Colonna M, Rimondini L. In vitro efficacy of a novel potassium oxalate hydrogel for dentin hypersensitivity. Eur J Oral Sci 2017; 125: 151-159.

5) Medvecky L, Stulajterova R, Giretova M, Mincik J, Vojtko M, Balko J, Briancin J. Effect of tetracalcium phosphate/ monetite toothpaste on dentin remineralization and tubule occlusion in vitro. Dent Mater 2017; 34: 442-451.

6) Feathestone JD. Remineralization, the natural caries repair process - the need for new approaches. Adv Dent Res 2009; 21: 4-7.

7) Anttonen V, Seppä L, Hausen H. Clinical study on the effect of professional cleaning of occlusal tooth surfaces on laser fluorescence measurements. Caries Res 2005; 39: 280-283.

8) Kohda N, Iijima M, Brantley WA, Muguruma T, Yuasa T, Nakagaki S, Mizoguchi I. Effects of bonding materials on the mechanical properties of enamel around orthodontic brackets. Angle Orthod 2012; 82: 187-195.

9) Tschoppe P, Zandim DL, Martus P, Kielbassa AM. Enamel and dentin remineralization by nano-hydroxyapatite toothpaste. J Dent 2011; 39: 430-437.

10) de Carvalho FG, Vieira BR, Santos RL, Carlo HL, Lopes PQ, de Lima BA. In vitro effects of nano-hydroxyapatite paste on initial enamel carious lesions. Pediatr Dent 2014; 36: 85-89.

11) Fujimoto Y, Iwasa M, Murayama R, Miyazaki M, Nagafuji A, Nakatsuka T. Detection of ions released from S-PRG fillers and their modulation effect. Dent Mater J 2010; 29: 392-397.

12) Ito S, Iijima M, Hashimoto $M$, Tsukamoto N, Mizoguchi I, Saito T. Effects of surface pre-reacted glass-ionomer fillers on mineral induction by phosphoprotein. J Dent 2011; 39: 7279 .

13) Iijima M, Ito S, Nakagaki S, Kohda N, Muguruma T, Saito T, Mizoguchi I. Effects of immersion in solution of an experimental toothpaste containing S-PRG filler on likeremineralization ability of etched enamel. Dent Mater J 2014; 33: 430-436.

14) Shiiya T, Tomiyama K, Iizuka J, Hasegawa H, Kuramochi E, Fujino F, Ohashi K, Nihei T, Teranaka T, Mukai Y. Effects 
of resin-based temporary filling materials against dentin demineralization. Dent Mater J 2016; 35: 70-75.

15) Iijima M, Kawaguchi K, Kawamura N, Ito S, Saito T, Mizoguchi I. The effects of single application of pastes containing ionreleasing particles on enamel demineralization. Dent Mater J 2017; 36: 461-468.

16) Czarnecka B, Limanowska-Shaw H, Nicholson JW. Buffering and ion-release by a glass-ionomer cement under near-neutral and acidic conditions. Biomaterials 2002; 23: 2783-2788.

17) Kaga M, Kakuda S, Ida Y, Toshima H, Hashimoto M, Endo K, Sano H. Inhibition of enamel demineralization by buffering effect of S-PRG filler containing dental sealant. Eur J Oral Sci 2014; 122: 78-83.

18) Dedhiya MG, Young F, Higuchi WI. Mechanism for the retardation of the acid dissolution rate of hydroxyapatite by strontium. J Dent Res 1973; 52: 1097-1109.

19) Featherstone JDB, Shields CP, Khademazad B, Oldershaw MD. Acid reactivity of carbonated apatite with strontium and fluoride substitutions. J Dent Res 1983; 62: 1049-1053.
20) de Almeida PDV, Grégio AM, Machado MA, de Lima AA, Azevedo LR. Saliva composition and functions: a comprehensive review. J Contemp Dent Pract 2008; 9: 72-80.

21) Luan Q, Desta T, Chehab L, Sanders VJ, Plattner J, Graves DT. Inhibition of experimental periodontitis by a topical boron-based antimicrobial. J Dent Res 2008; 87: 148-152.

22) LeGeros RZ, Parsons JR, Daculsi G, Driessens F, Lee D, Liu S, Metsger S, Peterson D. Significance of the porosity and physical chemistry of calcium phosphate ceramics. Biodegradation-bioresorption. Ann N Y Acad Sci 1988; 523: 268-271.

23) Zhang M, He LB, Exterkate RA, Cheng L, Li JY, Ten Cate JM, Crielaard W, Deng DM. Biofilm layers affect the treatment outcomes of $\mathrm{NaF}$ and Nano-hydroxyapatite. J Dent Res 2015; 94: 602-607.

24) Huang SB, Gao SS, Yu HY. Effect of nano-hydroxyapatite concentration on remineralization of initial enamel lesion in vitro. Biomed Mater 2009; 4: 1-6. 